\title{
Theoretical Study of the Dissociation Energy of First-Row Metallocenium Ions
}

\author{
Quan Manh Phung, Steven Vancoillie, and Kristine Pierloot* \\ Department of Chemistry, KU Leuven, Celestijnenlaan 200F, B-3001 Leuven, Belgium \\ E-mail: kristin.pierloot@chem.kuleuven.be
}

${ }^{*}$ To whom correspondence should be addressed 


\begin{abstract}
The bond dissociation energy of a series of metallocenium ions, i.e., the energy difference of the reaction $\mathrm{MCp}_{2}{ }^{+} \longrightarrow \mathrm{MCp}^{+}+\mathrm{Cp}^{\cdot}$ (with $\mathrm{M}=\mathrm{Ti}, \mathrm{V}, \mathrm{Cr}, \mathrm{Mn}$, $\mathrm{Fe}, \mathrm{Co}$, and $\mathrm{Ni}$ ), was studied by means of multiconfigurational perturbation theory (CASPT2, RASPT2, NEVPT2) and restricted coupled cluster theory (CCSD(T)). From a comparison between the results obtained from these different methods, and a detailed analysis of their treatment of electron correlation effects, a set of $\mathrm{MCp}^{+}$ Cp binding energies are proposed with an accuracy of $5 \mathrm{kcal} / \mathrm{mol}$. The computed results are in good agreement with the experimental data measured by threshold photoelectron photoion coincidence (TPEPICO) spectroscopy, but disagree with the more recent threshold collision-induced dissociation (TCID) experiments.
\end{abstract}




\section{Introduction}

Organometallic chemistry has a long history since the discovery of Cacodyl by Cadet in 1760. However, organometallic compounds had not been an important subject of study until the discovery of the first metallocene, i.e. ferrocene $\left(\mathrm{FeCp}_{2}\right)$ in $1951 .{ }^{1,2}$ One year later, Wilkinson ${ }^{3}$ described the geometry of this new molecule as a sandwich structure. Since then, other metallocene derivatives have been synthesized and studied. Their applications in many fields have been also discovered, ${ }^{4}$ such as in catalysis for olefin polymerization, in the fuel for petrol engines (antiknock agent), in molecular recognition (ferrocene/ferrocenium biosensor), in medicine (anti-tumor agents ${ }^{5}$ ), and in organic synthesis. The development of metallocene catalysis can be considered as the main key leading to the revolution of the plastic industry. ${ }^{6}$ With many important applications in industry, metallocenes have been the subject of numerous experimental studies. However, most of these studies focus on possible applications of metallocenes, while more fundamental properties, such as the thermochemistry of these compounds, are not well studied. To the best of our knowledge, the (homolytic and heterolytic) dissociation enthalpies of metallocenes $\mathrm{MCp}_{2}$ (with $\mathrm{M}=\mathrm{Fe}, \mathrm{V}, \mathrm{Mn}$, and $\mathrm{Ni}$ ) were measured only by Ryan et al. ${ }^{7}$ about 20 years ago. Before that time, the metal-cyclopentadienyl bond strength of the first-row metallocenium ions $\mathrm{MCp}_{2}{ }^{+}$had also been studied already. ${ }^{8}$ However, up until today, this property is still subject to debate. Indeed, thermochemical data for the metal-cyclopentadienyl bond strength in metallocenium ions show variations of several $\mathrm{eV}$, depending on the measurement method. ${ }^{8-10}$ The first extensive study was performed by Müller and D'or ${ }^{8}$ using electron ionization mass spectrometry (EIMS). The EIMS values are exceptionally high when compared to more recent values measured by threshold photoelectron photoion coincidence (TPEPICO) spectroscopy. ${ }^{10,11}$ In the latter study, two theories (Rice-Ramsperger-Kassel-Marcus, RRKM, ${ }^{12-15}$ and the simplified statistical adiabatic channel model, SSACM ${ }^{16}$ ) were used to extract the thermodynamics properties. Most recently, a new set of experimental bond dissociation energies (BDEs) of all firstrow metallocenium ions was reported by Rowland et al. ${ }^{9}$ using threshold collision-induced dissociation (TCID). This report also points to some problems in previous studies as the 
cause of unreliable BDEs. The TCID results are systematically lower than the TPEPICO results measured by Révész et al. ${ }^{10}$, and no rationalization was provided for the differences between both methods. Hence we believe that further investigation is needed.

Theoretical calculations have also been performed to study the metal-cyclopentadienyl bond strength in metallocenes. Both density functional theory (DFT) with different functionals (e.g. ref. 17) and wave function based methods (e.g. ref. 18) have been used. All studies agreed that DFT can not systematically yield reliable results. Depending on the chosen functional, DFT errors can be in the order of several $\mathrm{eV} .{ }^{17,18}$ The problem might be traced back to the fact that metallocenes often exhibit multiconfigurational character, that can only be treated by high quality wavefunction-based methods. In a previous study, ${ }^{18}$ we have shown that the heterolytic dissociation enthalpy $\left(\mathrm{MCp}_{2} \longrightarrow \mathrm{M}^{2+}+2 \mathrm{Cp}^{-}\right)$of various metallocenes $(\mathrm{M}=\mathrm{V}, \mathrm{Mn}, \mathrm{Fe}, \mathrm{Ni})$ can indeed be obtained with quantitative accuracy when making use of multiconfigurational perturbation theory, that is complete or restricted active space self-consistent field followed by second-order perturbation theory (CASSCF/CASPT2 and RASSCF/RASPT2). Only for vanadocene, RASPT2 was found to be less accurate, overestimating the dissociation enthalpy by $10 \mathrm{kcal} / \mathrm{mol}$. In this work, we make use of the same methods to calculate the BDEs of the first-row metallocenium ions: $\mathrm{MCp}_{2}^{+} \longrightarrow \mathrm{MCp}^{+}+\mathrm{Cp}, \mathrm{M}=\mathrm{Ti}-\mathrm{Ni}$. Moreover, we also make use of the alternative NEVPT2 method ('n-electron valence state perturbation theory'), ${ }^{19-21}$ which uses a different zeroth-order Hamiltonian, and of coupled cluster theory with singles, doubles and perturbative triples $(\operatorname{CCSD}(\mathrm{T}))$, which is considered the 'gold' standard in quantum chemistry. By comparing the results obtained with this series of high-quality ab initio methods, making use of extensive basis sets, we expect to obtain estimates for the BDEs of the first-row metallocene ions that are accurate to within a few $\mathrm{kcal} / \mathrm{mol}$. As such, the results from the present computational study should be valuable as a benchmark for future experimental measurements. 


\section{Computational Details}

As it is computationally unfeasible to optimize the metallocene structures with multiconfigurational perturbation theory or coupled-cluster theory, the ground state geometry of the metallocenes $\mathrm{MCp}_{2}{ }^{+}$and its two fragments $\mathrm{MCp}^{+}$and $\mathrm{Cp}$, were optimized using DFT with a PBE0 functional. ${ }^{22}$ These calculations were performed with the TURBOMOLE v6.04 ${ }^{23}$ program, making use of def2-TZVP basis sets for $\mathrm{C}$ and $\mathrm{H},{ }^{24}$ and def2-QZVPP basis sets for the metal atoms. ${ }^{25}$ All molecules were optimized with the default thresholds in TURBOMOLE, and including dispersion correction. ${ }^{26}$ Frequency calculations were performed to confirm that the calculated structures of the molecules indeed correspond to minima on the potential energy surface (PES) and to obtain the zero-point energy $\left(E_{\mathrm{ZPE}}\right)$ correction.

The binding energies were computed with MP2, CASPT2, RASPT2, NEVPT2, and $\mathrm{CCSD}(\mathrm{T})$ as the energy difference for the following reaction: $\mathrm{MCp}_{2}{ }^{+} \longrightarrow \mathrm{MCp}^{+}+\mathrm{Cp}$. In these calculations, all valence electrons as well as the metal (3s,3p) semi-core electrons were correlated, and scalar relativistic effects were included using the standard 2nd-order Douglas-Kroll-Hess Hamiltonian. ${ }^{27,28}$

All CASSCF/CASPT2 and RASSCF/RASPT2 calculations were performed with the MOLCAS 7.6 package. ${ }^{29}$ ANO-RCC basis sets with a total of 1367 basis functions were used with the following contractions: [10s9p8d6f4g2h] for the metal atom, ${ }^{30}$ [8s7p4d3f1g] for carbon, ${ }^{31}$ and [6s4p3d1f] for hydrogen. ${ }^{32}$ This basis set was shown to be large enough to yield reliable results for the dissociation energy of first-row metallocenes. ${ }^{18,33}$ To approximate the two-electron integrals, the Cholesky decomposition technique with a threshold of $10^{-6}$ a.u. was used. ${ }^{34,35}$ The default IPEA shift for the zeroth-order Hamil$\operatorname{tonian}^{36}$ (0.25 a.u.) was used and an imaginary level shift ${ }^{37}$ of 0.1 a.u. was used to prevent intruder states.

The active spaces used in the calculations on $\mathrm{MCp}_{2}{ }^{+}, \mathrm{MCp}^{+}$, and $\mathrm{Cp}$ are described in Figures 1, 2, and 3, respectively. In a previous study ${ }^{18}$ we have shown that using these active spaces an accurate heterolytic dissociation energy of various metallocenes may be obtained, and a more detailed discussion on how the metal $3 \mathrm{~d}$ and $\mathrm{Cp}\left(\pi, \pi^{*}\right)$ valence 
orbitals are distributed over the active (sub)space(s) may be found there. Note that the "3d double-shell effect" ${ }^{38-40}$ is accounted for in the RASSCF (but not the CASSCF) calculations, by including five $3 \mathrm{~d}^{\prime}$ orbitals in the RAS3 space of all metals containing five or more 3d electrons $(\mathrm{Mn}-\mathrm{Ni})$, and allowing up to double excitations into this subspace. For Ti-Cr, the double-shell effect is of minor importance because the $3 \mathrm{~d}$ shell is less-thanhalf filled, and, when included in the active space, the $3 \mathrm{~d}^{\prime}$ orbitals would tend to rotate into other diffuse orbitals, e.g. C 3p, making the RASSCF description unbalanced. For these metals, the $3 \mathrm{~d}^{\prime}$ orbitals were therefore omitted from the active space. Also note that part of the $(3 \mathrm{~s}, 3 \mathrm{p})$ correlation contribution to the dissociation energy was accounted for already in the reference wave function of all RASPT2 (but not the CASPT2) calculations, by including the (3s,3p) orbitals in RAS1 and allowing SD excitations out of this subspace.

All MP2, partially contracted $n$-electron valence state perturbation theory (PC-NEVPT2) calculations and partially spin restricted open-shell $\operatorname{CCSD}(\mathrm{T})$ calculations, based on restricted open-shell ROHF orbitals, were performed with the MOLPRO $2009^{41}$ package. Extensive Dunning correlation consistent (cc) basis sets were used: aug-cc-pwcVQZ-DK for the metal, ${ }^{42}$ which is especially designed to treat the $(3 \mathrm{~s}, 3 \mathrm{p})$ correlation, aug-cc-pVTZDK for C, ${ }^{43}$ and cc-pVTZ-DK for H. ${ }^{44}$

\section{Results and Discussion}

\section{Electronic structure and geometry of $\mathrm{MCp}^{+}$and $\mathrm{MCp}_{2}{ }^{+}$}

Depending on the distribution of the d electrons over the (predominantly) metal 3d orbitals, the ground state of the considered metallocenium ions can be either low-spin (LS), intermediate-spin (IS) or high-spin (HS). The (main) electronic configuration and symmetry label of the ground state of the various ions, obtained after checking the relative spin state energetics by means of (PBE0) DFT, is schematically presented in Figure $4 .{ }^{45}$ The results of the PBE0 calculations are presented in the Supporting Information. It is well-known that DFT is not very reliable when it comes to predicting relative energies of different spin states in transition metal complexes, providing results that may be 


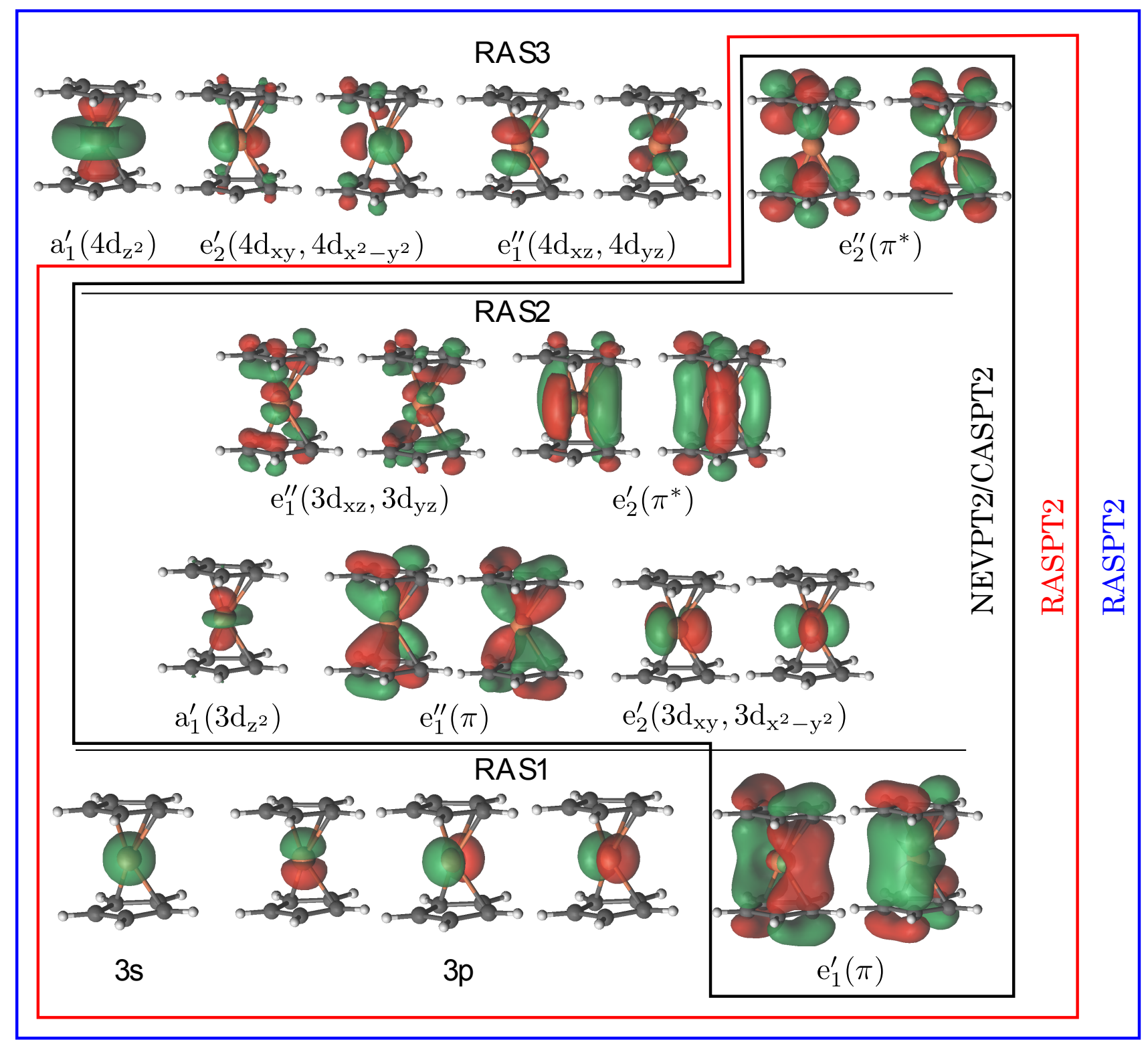

Figure 1: The active space of $\mathrm{MnCp}_{2}{ }^{+}, \mathrm{FeCp}_{2}{ }^{+}, \mathrm{CoCp}_{2}{ }^{+}, \mathrm{NiCp}_{2}{ }^{+}$(blue), $\mathrm{TiCp}_{2}{ }^{+}, \mathrm{VCp}_{2}{ }^{+}$, $\mathrm{CrCp}_{2}{ }^{+}$(red) in RASPT2 calculations and $\mathrm{TiCp}_{2}{ }^{+}, \mathrm{VCp}_{2}{ }^{+}, \mathrm{CrCp}_{2}{ }^{+}$(black) in NEVPT2 and CASPT2 calculations 


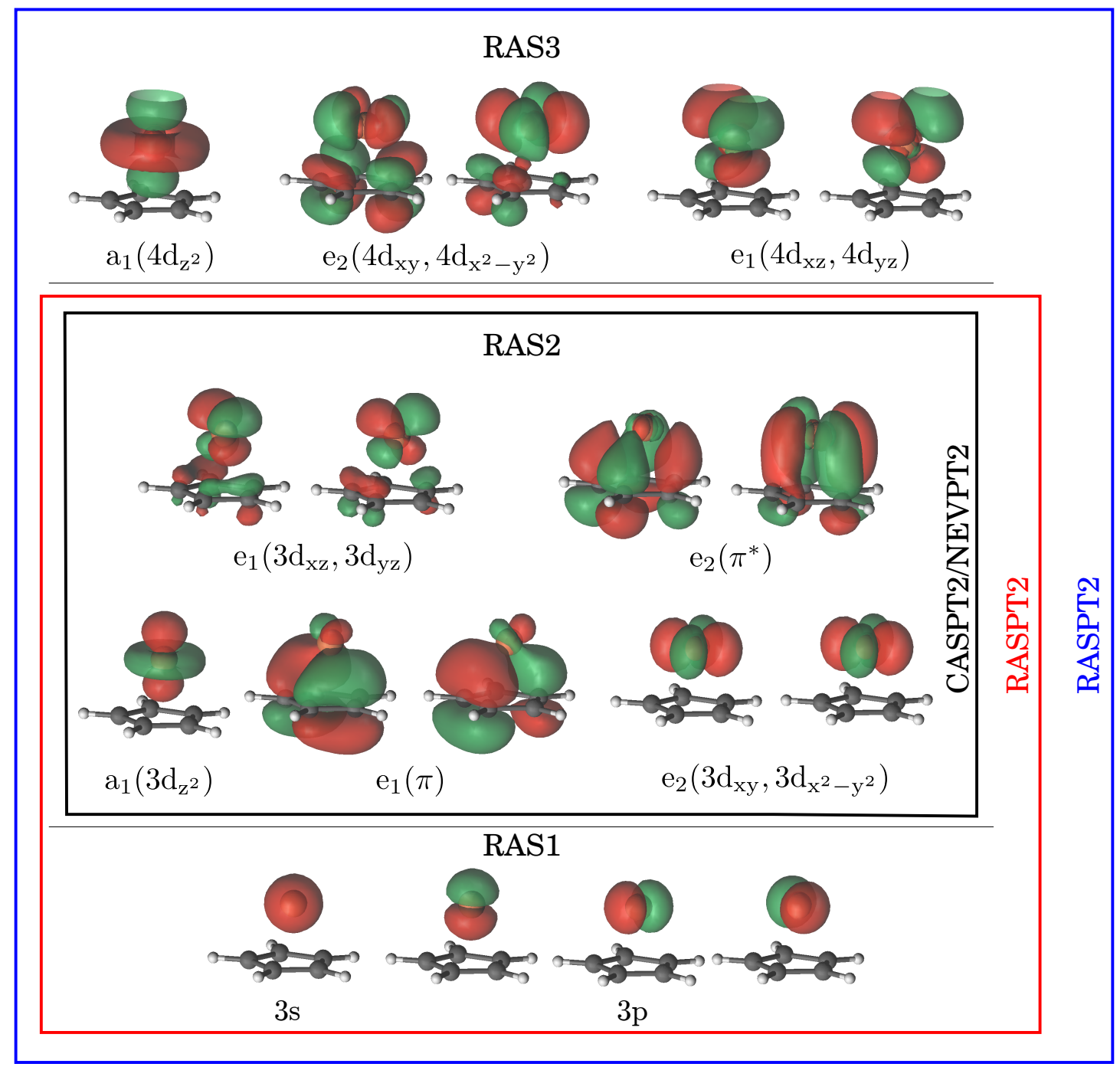

Figure 2: The active space of $\mathrm{MnCp}^{+}, \mathrm{FeCp}^{+}, \mathrm{CoCp}^{+}, \mathrm{NiCp}^{+}$(blue), $\mathrm{TiCp}^{+}, \mathrm{VCp}^{+}$, $\mathrm{CrCp}^{+}$(red) in RASPT2 calculations and $\mathrm{TiCp}^{+}, \mathrm{VCp}^{+}, \mathrm{CrCp}^{+}$(black) in NEVPT2 and CASPT2 calculations

RAS2
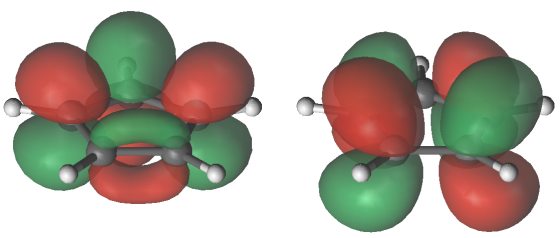

$\pi^{*}$
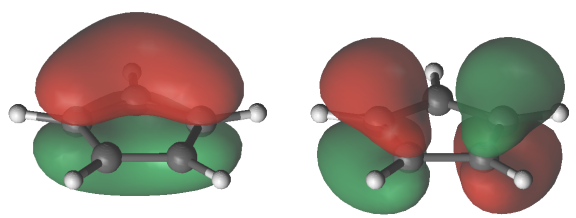

$\pi$

Figure 3: The active space of $\mathrm{Cp}^{*}$ in RASPT2 and NEVPT2 calculations 
strongly functional dependent. As such, the results provided in Table S1 should only be considered as a rough estimate. In most cases, though, the energy differences reported are large enough $(>15 \mathrm{kcal} / \mathrm{mol})$ to allow for a reliable prediction of the ground state spin multiplicity in the considered complexes. In those cases where alternative spin states are predicted at lower energies (e.g. $\mathrm{CoCp}^{+}$), RASPT2 calculations were performed to confirm the character of the ground state. In one case, i.e. $\mathrm{MnCp}_{2}{ }^{+}$, the ground state is predicted to be IS $\left({ }^{3} \mathrm{E}_{1}^{\prime}\right)$ by PBE0, but with a quintet state $\left({ }^{5} \mathrm{E}_{2}^{\prime \prime}\right)$ at only $3.3 \mathrm{kcal} / \mathrm{mol}$. For this reason, both states are included in Figure 4, and were considered as possible ground state candidates in the more elaborate correlated calculations.

The PBE0 structural data of the various $\mathrm{MCp}_{2}{ }^{+}$and $\mathrm{MCp}^{+}$complexes are presented in Table 1. The structures are characterized by the distance between the metal atom and the cyclopentadienyl ring $\left(\mathrm{d}_{\mathrm{M}-\mathrm{Cp}}\right)$, and by the angle between the two cyclopentadienyl rings. With exception of $\mathrm{TiCp}_{2}{ }^{+}$and $\mathrm{VCp}_{2}{ }^{+}$, the $\mathrm{MCp}_{2}{ }^{+}$complexes essentially have $\mathrm{D}_{5 \mathrm{~h}}$ symmetry, although those with a degenerate ground state do undergo a small Jahn-Teller distortion ( to $\mathrm{C}_{2 \mathrm{v}}$ ), manifested by a deviation from coplanarity in the angle between the two cyclopentadienyl rings. For these complexes, we have therefore kept the state labeling in $\mathrm{D}_{5 \mathrm{~h}}$ symmetry. A much stronger distortion from $\mathrm{D}_{5 \mathrm{~h}}$ is found for $\mathrm{TiCp}_{2}{ }^{+}$and $\mathrm{VCp}_{2}{ }^{+}$, the angle between the Cp rings becoming 26-29 degrees. Therefore, labels corresponding to the actual $\mathrm{C}_{2 \mathrm{v}}$ were used for these two molecules (Figure 4). Experimentally, the latter two compounds are also much less stable than the other metallocene ions and the metal atom can readily bind with other ligands to saturate the dangling bond. ${ }^{46}$ Hence, the thermochemistry of $\mathrm{TiCp}_{2}{ }^{+}$and $\mathrm{VCp}_{2}{ }^{+}$is not well studied. The ground state of the $\mathrm{MCp}^{+}$ions is $\mathrm{HS}$ in all cases, and all these complexes have $\mathrm{C}_{\mathrm{s}}$ symmetry (but very close to $\mathrm{C}_{5 \mathrm{v}}$ symmetry). Thus, the symmetry labeling corresponds to the ideal $\mathrm{C}_{5 \mathrm{v}}$ symmetry.

As can be seen from Table 1 the $\mathrm{M}-\mathrm{Cp}$ distance in $\mathrm{MCp}_{2}^{+}$is smallest for $\mathrm{CoCp}_{2}{ }^{+}$. This conforms to the fact that this molecule fulfills the 18-electron rule, and it is therefore also expected to have the strongest $\mathrm{MCp}^{+}-\mathrm{Cp}$ bond. In the surrounding metallocenium ions, the $\mathrm{M}-\mathrm{Cp}$ distance becomes longer as the number of valence electrons deviates more from 18, and the $\mathrm{MCp}^{+}-\mathrm{Cp}$ bond becomes weaker than the $\mathrm{CoCp}^{+}-\mathrm{Cp}$ bond (see further 


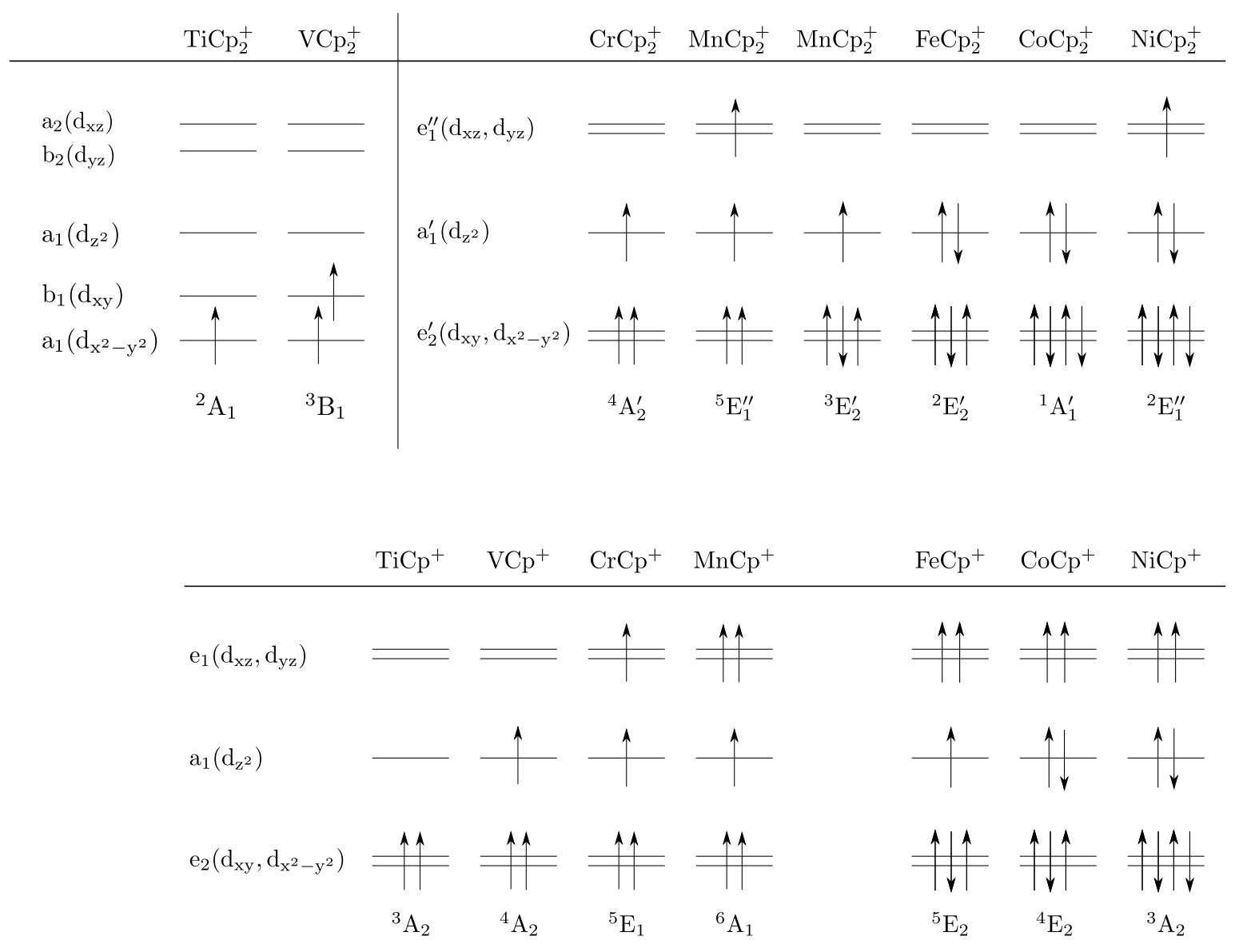

Figure 4: Electronic configuration of $\mathrm{MCp}_{2}{ }^{+}$and $\mathrm{MCp}^{+}$ 
in Table 2). As all $\mathrm{MCp}^{+}$ions are HS, whereas most $\mathrm{MCp}_{2}{ }^{+}$complexes tend to have a LS or IS ground state, dissociation of a Cp ligand in several cases turns an empty $\mathrm{e}_{1}^{\prime \prime}\left(\mathrm{d}_{x z}, \mathrm{~d}_{y z}\right)$ shell into a doubly occupied $\mathrm{e}_{1}\left(\mathrm{~d}_{x z}, \mathrm{~d}_{y z}\right)$ shell. As these orbitals are antibonding, this gives rise to a bond lengthening of the remaining $\mathrm{M}-\mathrm{Cp}$ bond by more than $0.1 \AA$, as in the case for $\mathrm{MnCp}_{2}{ }^{+}\left({ }^{3} \mathrm{E}_{2}^{\prime}\right), \mathrm{FeCp}_{2}{ }^{+}$, and $\mathrm{CoCp}_{2}{ }^{+}$. A smaller bond lengthening, by 0.05 $\AA$, is found for $\mathrm{CrCp}_{2}{ }^{+}$, where the dissociation of $\mathrm{Cp}$ provides a first electron into the antibonding $\mathrm{e}_{1}$ shell. In cases where $\mathrm{e}_{1}$ remains empty $\left(\mathrm{TiCp}_{2}{ }^{+}\right.$, and $\left.\mathrm{VCp}_{2}{ }^{+}\right)$or changes occupation from one to two $\left(\mathrm{MnCp}_{2}{ }^{+}\left({ }^{5} \mathrm{E}_{2}^{\prime \prime}\right), \mathrm{NiCp}_{2}{ }^{+}\right)$a slight shortening $(0.01-0.05 \AA)$ of the remaining $\mathrm{M}-\mathrm{Cp}$ bond is observed upon dissociation of a $\mathrm{Cp}$ ligand.

Table 1: Geometry of $\mathrm{MCp}^{+}$and $\mathrm{MCp}_{2}{ }^{+}$computed with the PBE0 functional. The bond distances are in Angstrom, the angles are in degrees

\begin{tabular}{|c|c|c|c|}
\hline \multirow[t]{2}{*}{$\overline{\mathrm{M}}$} & $\mathrm{MCp}^{+}$ & \multicolumn{2}{|c|}{$\mathrm{MCp}_{2}{ }^{+}$} \\
\hline & $\mathrm{d}_{\mathrm{M}-\mathrm{Cp}}$ & $\mathrm{d}_{\mathrm{M}-\mathrm{Cp}}$ & $\measuredangle \mathrm{Cp}-\mathrm{Cp}^{a}$ \\
\hline$\overline{\mathrm{Ti}}$ & 1.947 & 1.976 & 29.3 \\
\hline V & 1.859 & 1.903 & 26.6 \\
\hline $\mathrm{Cr}$ & 1.901 & 1.856 & 0.00 \\
\hline $\mathrm{Mn}(\mathrm{HS})$ & 1.905 & 1.937 & 6.94 \\
\hline $\operatorname{Mn}(\mathrm{LS})$ & 1.905 & 1.763 & 6.24 \\
\hline $\mathrm{Fe}$ & 1.822 & 1.713 & 4.82 \\
\hline Co & 1.774 & 1.642 & 0.00 \\
\hline $\mathrm{Ni}$ & 1.720 & 1.732 & 0.30 \\
\hline
\end{tabular}

\section{$\mathrm{MCp}^{+}-\mathrm{Cp}$ bond dissociation energy of $\mathrm{MCp}_{2}{ }^{+}$}

In Table 2, the $\mathrm{MCp}^{+}-\mathrm{Cp}$ bond dissociation energies computed with different correlated wave function methods (MP2, NEVPT2, CASPT2, RASPT2, CCSD(T)) are summarized. In the first part of the discussion, we will compare the results of the different methods and analyze possible origins of any discrepancies, so as to establish the most reliable computed values. As an aid for this analysis, we have provided in Table 3 a series of data that are related to the multireference character of the wave function, and may be therefore serve to estimate the quality of the different correlation methods, i.e. the $T_{1}, D_{1}$ diagnostics 
obtained from the CCSD wave function, the weight of the leading configuration state function in the RASSCF wave function $\mathrm{C}_{0}^{2}$, and the RASSCF reference weight in the RASPT2 wave function $\mathrm{C}_{1}^{2}$. In the second part, the computed dissociation energies are compared to the different experimental results obtained by the TCID and TPEPICO measurements, which are listed in Table 2 as well.

\section{Comparison of the computed binding energies}

A general observation from Table 2 is that all methods based on perturbation theory systematically predict larger binding energies than $\operatorname{CCSD}(\mathrm{T})$. Apart from this, a different behavior is observed for different correlation methods between three groups of transition metals (TM), which will therefore be discussed separately. The three groups are (A) the late TM: Fe, Co, Ni; (B) the early TM: Ti, V, Cr; and (C) Mn.

Looking first at group (A) we find an excellent agreement between the two most elaborate correlation methods considered in this work, either RASPT2 and CCSD(T), with differences in binding energies between both methods of at most $3 \mathrm{kcal} / \mathrm{mol}$. The results obtained from MP2 are much larger, by $20 \mathrm{kcal} / \mathrm{mol}$ for $\mathrm{FeCp}_{2}{ }^{+}$to $45 \mathrm{kcal} / \mathrm{mol}$ for CoCp ${ }_{2}{ }^{+}$, and by more than $50 \mathrm{kcal} / \mathrm{mol}$ for $\mathrm{NiCp}_{2}{ }^{+}$. The large differences between MP2 and RASPT2 clearly point to the occurrence of non-dynamical correlation effects that cannot be treated accurately by second-order perturbation theory, but rather have to be treated variationally in the reference wave function. Similar differences were found in previous studies on the binding energy of neutral ferrocene. ${ }^{18,33,47}$ In ref. 47 it was shown that MP2 grossly overestimates the binding energy, and that including the bonding and antibonding Fe 3d-ligand combinations in the active space of a CASSCF reference wave function (i.e. $\mathrm{e}_{1}^{\prime \prime}(\pi), \mathrm{e}_{1}^{\prime \prime}\left(3 \mathrm{~d}_{x z}, 3 \mathrm{~d}_{y z}\right), \mathrm{e}_{2}^{\prime}\left(3 \mathrm{~d}_{x y}, 3 \mathrm{~d}_{x^{2}-y^{2}}\right), \mathrm{e}_{2}^{\prime}\left(\pi^{*}\right)$ in Figure 1$)$ is a prerequisite for obtaining at least qualitative accuracy. In two recent studies ${ }^{18,33}$ we have shown that the accuracy on the binding energy may be further improved (to within $5 \mathrm{kcal} / \mathrm{mol}$ or less) by making use of an extended active space, as shown in Figure 1. However, even though non-dynamical correlation effects are obviously important in these late TM metallocenium ions, the close correspondence between RASPT2 and CCSD(T) indicates 


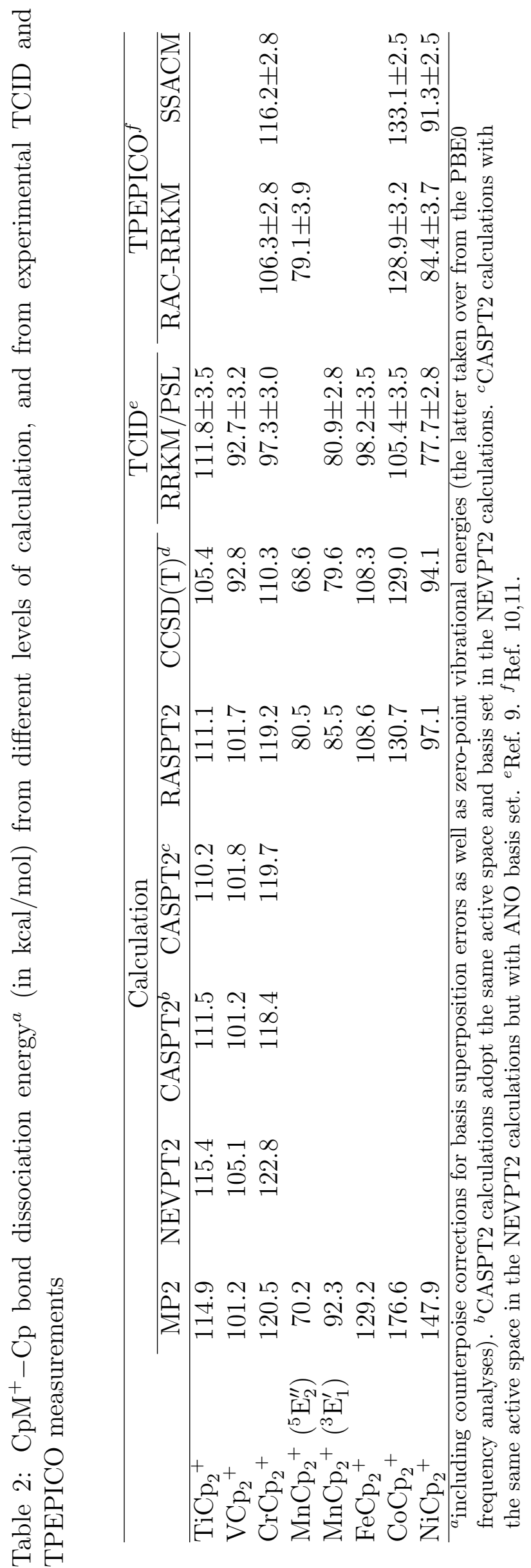


Table 3: Analysis of the CCSD, RASSCF, and RASPT2 wave functions

\begin{tabular}{lrrrr}
\hline & $\mathrm{T}_{1}{ }^{a}$ & $\mathrm{D}_{1}{ }^{a}$ & $\mathrm{C}_{0}^{2}{ }^{b}$ & $\mathrm{C}_{1}^{2}{ }^{c}$ \\
\hline $\mathrm{TiCp}_{2}{ }^{+}$ & 0.018 & 0.078 & 0.899 & 0.626 \\
$\mathrm{VCp}_{2}{ }^{+}$ & 0.030 & 0.145 & 0.880 & 0.621 \\
$\mathrm{CrCp}_{2}{ }^{+}$ & 0.026 & 0.119 & 0.878 & 0.614 \\
$\mathrm{MnCp}_{2}{ }^{+}\left({ }^{5} \mathrm{E}_{2}^{\prime \prime}\right)$ & 0.026 & 0.155 & 0.776 & 0.621 \\
$\mathrm{MnCp}_{2}{ }^{+}\left({ }^{3} \mathrm{E}_{1}^{\prime}\right)$ & 0.034 & 0.146 & 0.804 & 0.625 \\
$\mathrm{FeCp}_{2}{ }^{+}$ & 0.037 & 0.168 & 0.822 & 0.629 \\
$\mathrm{CoCp}_{2}{ }^{+}$ & 0.042 & 0.183 & 0.813 & 0.631 \\
$\mathrm{NiCp}_{2}{ }^{+}$ & 0.031 & 0.180 & 0.824 & 0.629 \\
\hline $\mathrm{TiCp}^{+}$ & 0.021 & 0.068 & 0.937 & 0.757 \\
$\mathrm{VCp}^{+}$ & 0.026 & 0.095 & 0.934 & 0.749 \\
$\mathrm{CrCp}^{+}$ & 0.030 & 0.156 & 0.936 & 0.741 \\
$\mathrm{MnCp}^{+}$ & 0.021 & 0.075 & 0.936 & 0.755 \\
$\mathrm{FeCp}^{+}$ & 0.030 & 0.118 & 0.924 & 0.754 \\
$\mathrm{CoCp}^{+}$ & 0.036 & 0.149 & 0.922 & 0.755 \\
$\mathrm{NiCp}^{+}$ & 0.050 & 0.217 & 0.891 & 0.758 \\
\hline $\mathrm{T}_{1}$ and $\mathrm{D}_{1}$ diagnostics computed for the CCSD \\
wave function. ${ }^{b}$ The weight of leading configura- \\
tion of the RASSCF wave function. ${ }^{c}$ The reference \\
weight in the RASPT2 wave function.
\end{tabular}

that these correlation effects are in fact accurately described by the latter single reference method.

For the early TM, group (B), the differences between RASPT2 and CCSD(T) become significantly larger, from $5.7 \mathrm{kcal} / \mathrm{mol}$ for $\mathrm{TiCp}_{2}{ }^{+}$to $8.9 \mathrm{kcal} / \mathrm{mol}$ for $\mathrm{VCp}_{2}{ }^{+}$and $\mathrm{CrCp}_{2}{ }^{+}$. Notably, however, both sets of results are now considerably closer to MP2. In particular, the difference between MP2 and RASPT2 is small, only $0.3-3.8 \mathrm{kcal} / \mathrm{mol}$. This is a first indication that non-dynamic correlation effects are considerably less important in these complexes than for the late TM. A second indication comes from the coupled cluster diagnostics $T_{1} / D_{1}$, shown in Table 3. It has been suggested by Jiang et al. ${ }^{48}$ that for transition metal complexes the combination of values for $\mathrm{T}_{1}<0.05$ and $\mathrm{D}_{1}<0.15$ should assure minor multireference effects and an accurate behavior of the $\operatorname{CCSD}(\mathrm{T})$ method. In cases where one or even both of these criteria are not met, the multireference character is more pronounced, although this does not necessarily mean that $\operatorname{CCSD}(\mathrm{T})$ should fail. For example, in a comparative study between single-reference and reduced multireference $\operatorname{CCSD}(\mathrm{T})$ for a series of small TM complexes $\mathrm{MCH}_{2}^{+}$it was found that the difference 
in binding energy obtained from both methods never amounts to more than $2 \mathrm{kcal} / \mathrm{mol}$, even in cases with substantial near-degeneracies. ${ }^{49}$ From Table 3 one can see that for the early-transition metal metallocenes $\left(\mathrm{Ti}, \mathrm{V}\right.$, and $\mathrm{Cr}$ ) both $\mathrm{T}_{1}$ and $\mathrm{D}_{1}$ strictly meet the criteria of Jiang et al. ${ }^{48}$, while they both increase towards the right side of the series, pointing to multiconfigurational effects becoming increasingly more important. As such, we believe that the $\mathrm{CCSD}(\mathrm{T})$ results obtained for $\mathrm{TiCp}_{2}{ }^{+}, \mathrm{VCp}_{2}{ }^{+}$, and $\mathrm{CrCp}_{2}{ }^{+}$, should be considered of similar or even higher accuracy than the results obtained for the late TM.

This then also means that RASPT2 significantly overestimates the binding energy of the early TM metallocenium ions. A similar phenomenon has already been observed in our previous study on the (heterolytic) dissociation enthalpy of the neutral metallocenes $\mathrm{MCp}_{2}(\mathrm{M}=\mathrm{V}, \mathrm{Mn}, \mathrm{Fe}, \mathrm{Ni}) .{ }^{18}$ Also there RASPT2 was found to overestimate the binding energy for $\mathrm{VCp}_{2}$ by $10 \mathrm{kcal} / \mathrm{mol}$, while performing excellently for the later TM. In order to investigate this further, we decided to recalculate the heterolytic dissociation enthalpy of vanadocene $\left(\mathrm{VCp}_{2} \longrightarrow \mathrm{V}^{2+}+2 \mathrm{Cp}^{-}\right)$by means of $\mathrm{CCSD}(\mathrm{T})$. A value of $606.3 \mathrm{kcal} / \mathrm{mol}$ was obtained from this method, lower by $9.3 \mathrm{kcal} / \mathrm{mol}$ than our previous RASPT2 result of $615.6 \mathrm{kcal} / \mathrm{mol}$, and in excellent correspondence with the experimental value of $606 \pm 6 \mathrm{kcal} / \mathrm{mol}^{7}$

If RASPT2 does not provide the expected accuracy, a first and obvious cause to be investigated is whether the active space used to construct the reference wave function is really adequate, i.e. does include all important correlation effects. In first-row TM complexes, two possible sources of strong correlation effects are well-known. The first is the so-called double-shell effect. This correlation effect is, however, particularly important only for TM with a more-than-half filled $3 \mathrm{~d}$ shell, not for the early TM. In fact, for $\mathrm{M}=$ Ti, V, and Cr we did not include a second d-shell, which would incorporate this doubleshell effect, in the active space of the $\mathrm{MCp}_{2}{ }^{+}$and $\mathrm{MCp}^{+}$ions (see Figures 1 and 2). Any attempt to include such orbitals fails (i.e. they rotate into other virtual orbitals, such as C 3p), precisely because the double-shell effect is not important enough to keep them active. A second important correlation effect in TM complexes is connected to covalent 
3d-ligand bonds, and should be treated in the reference wave function by including both the bonding and antibonding combinations involved in such bonds in the RAS2 space. In the present metallocenium ions the metal-Cp bonds are formed by charge donation from the occupied Cp $\pi$ orbitals into the $\left(3 \mathrm{~d}_{x z}, 3 \mathrm{~d}_{y z}\right)$ orbitals within the $\mathrm{e}_{1}^{\prime \prime}$ representation $\left(\mathrm{e}_{1}\right.$ in $\left.\mathrm{MCp}^{+}\right)$and from the $\left(3 \mathrm{~d}_{x y}, 3 \mathrm{~d}_{x^{2}-y^{2}}\right)$ orbitals into $\mathrm{Cp} \pi^{*}$ within $\mathrm{e}_{2}^{\prime}\left(\mathrm{e}_{2}\right.$ in $\left.\mathrm{MCp}^{+}\right)$, and these eight orbitals have therefore been included in RAS2 in all cases. However, also this static correlation effect becomes less important when moving from the right to the left side of the TM series, as the metal-ligand bonds tend to become less covalent. As can be seen from Table 3, the weight of the leading CSF in the RASSCF wave function $\left(\mathrm{C}_{0}^{2}\right)$ is consistently higher for the early TM $(0.88-0.90)$ than for the late $\mathrm{TM} \mathrm{MCp}_{2}{ }^{+}$complexes (0.80-0.82), thus again showing that multiconfigurational effects are weaker at the left side of the series.

Another important correlation effect to be considered with care concerns the correlation of the semi-core $(3 \mathrm{~s}, 3 \mathrm{p})$ electrons. For the heterolytic dissociation of ferrocene, for example, we found ${ }^{33}$ that correlating the $(3 \mathrm{~s}, 3 \mathrm{p})$ electrons gives rise to a bond strengthening by as much as $15 \mathrm{kcal} / \mathrm{mol}$. It has also been shown ${ }^{49}$ that $(3 \mathrm{~s}, 3 \mathrm{p})$ correlation more strongly affects the metal-ligand binding energy for early than for the late $3 \mathrm{~d}$ TM. When using multiconfigurational perturbation theory a choice can be made whether to treat $(3 \mathrm{~s}, 3 \mathrm{p})$ correlation perturbationally in the PT2 step, or variationally in the reference wave function, by including $(3 \mathrm{~s}, 3 \mathrm{p})$ orbitals in the active space. The latter option should give more accurate results, and was found to give rise to an important improvement (by more than $5 \mathrm{kcal} / \mathrm{mol}$ ) of the (heterolytic) dissociation energy of vanadocene. All RASPT2 results in Table 2 were obtained with an active space including the $3 \mathrm{~s}$ and $3 \mathrm{p}$ orbitals in RAS1, but the effect of doing so was found to be rather small, only around $2 \mathrm{kcal} / \mathrm{mol}$ at most (cfr the SI, where we have included RASPT2 results with (3s,3p) correlation treated perturbationally instead). For the early TM, CASPT2 results are also presented in Table 2, in which $(3 \mathrm{~s}, 3 \mathrm{p})$ correlation was moved to the perturbational step. As one can see, the effect of doing so is insignificant, less than $1 \mathrm{kcal} / \mathrm{mol}$.

We finally note that the weight of the RASSCF reference weight in the RASPT2 wave 
function, $\mathrm{C}_{1}^{2}$ in Table 3, remains virtually constant across the TM series. This is another confirmation that an equal fraction of the correlation is included in the RASSCF step for all TM, and that the seemingly lower quality of the RASPT2 treatment for the early TM is not caused by the occurrence of so-called 'intruder states', i.e. states that should have been included in the reference to assure an accurate perturbational treatment. On the whole, we may therefore conclude that no significant improvement of the PT2 results for the binding energies of $\mathrm{TiCp}_{2}{ }^{+}, \mathrm{VCp}_{2}{ }^{+}$, and $\mathrm{CrCp}_{2}{ }^{+}$are to be expected from any further changes of the active space beyond the one presented in Figures 1 and 2 .

In an additional effort to understand the remaining difference between the $\mathrm{R}(\mathrm{C}) \mathrm{ASPT} 2$ results and $\operatorname{CCSD}(\mathrm{T})$ we decide to investigate the effect of zeroth-order Hamiltonian of the PT2 treatment, by replacing CASPT2 by the alternative NEVPT2 method. However, it was found (Table 2) that the NEVPT2 binding energies deviate even more strongly from CCSD $(\mathrm{T})$ than the CASPT2/RASPT2 or even the MP2 results. This leads us to conclude that for these early metallocenium ions the second-order perturbational treatment in se is insufficient, regardless of the extension of the reference or the formulation of the zeroth-order Hamiltonian, and that higher orders of perturbation theory are necessary to bring the results closer to $\operatorname{CCSD}(\mathrm{T})$.

Finally, we turn to $\mathrm{MnCp}_{2}{ }^{+}$. Experimentally, this molecule has a triplet ground state. This is confirmed by all three computational methods. However, the energy difference between the calculated ${ }^{3} \mathrm{E}_{1}^{\prime}$ ground state and the lowest-lying high-spin state ${ }^{5} \mathrm{E}_{2}^{\prime \prime}$ differs quite strongly between the different methods. With RASPT2 the ${ }^{5} \mathrm{E}_{2}^{\prime \prime}$ state is predicted to be low-lying, at only $5 \mathrm{kcal} / \mathrm{mol}$, whereas a much considerably larger splitting is predicted by the other methods, $11 \mathrm{kcal} / \mathrm{mol}$ by $\operatorname{CCSD}(\mathrm{T})$, and more than $22 \mathrm{kcal} / \mathrm{mol}$ by MP2. Consequently (as both states dissociate to the same ${ }^{6} \mathrm{~A}_{1}$ state in $\mathrm{MnCp}^{+}$) considerable differences are also found between the binding energies predicted by the different methods. As compared to RASPT2, MP2 predicts a higher binding energy for low-spin $\mathrm{MnCp}_{2}{ }^{+}$(by $6.8 \mathrm{kcal} / \mathrm{mol}$ ), but a lower binding energy for high-spin $\mathrm{MnCp}_{2}{ }^{+}$(by $10.3 \mathrm{kcal} / \mathrm{mol}$ ). Obviously, the variational treatment of non-dynamical correlation effects is of primary importance to obtain an accurate prediction of the spin state energetics in 
this complex by second-order perturbation theory, as has been shown previously in several other cases. ${ }^{33,50-53}$ With $\operatorname{CCSD}(\mathrm{T})$ the binding energy predicted for the ${ }^{3} \mathrm{E}_{1}^{\prime}$ ground state, $79.6 \mathrm{kcal} / \mathrm{mol}$, is lower by around $6 \mathrm{kcal} / \mathrm{mol}$ than with RASPT2. This difference seems to be consistent with the other metals, i.e. it is smaller than for the early TM, but larger than for the late TM. However, for the ${ }^{5} \mathrm{E}_{2}^{\prime \prime}$ state the difference between RASPT2 and $\operatorname{CCSD}(\mathrm{T})$ amounts to almost $12 \mathrm{kcal} / \mathrm{mol}$, which is larger than for any other metal. In this case, there is in fact a strong indication that $\operatorname{CCSD}(\mathrm{T})$ might not perform equally well as for the other TM. Indeed, looking at Table 3 we find that the weight of the leading CSF in the RASSCF wave function of the ${ }^{5} \mathrm{E}_{2}^{\prime \prime}$ state, 0.776 , is considerably lower than for the ${ }^{3} \mathrm{E}_{1}^{\prime}$ state in the same molecule as well as for all other metallocenium ions, with $\mathrm{C}_{0}^{2}$ values between between 0.8 and 0.9 . This clearly points to more severe multiconfigurational effects for the ${ }^{5} \mathrm{E}_{2}^{\prime \prime}$ state, which may deteriorate the $\operatorname{CCSD}(\mathrm{T})$ result for this state. As can be seen from the table with the natural orbital occupation numbers in the SI (Table S11) the orbital pair involved in the increased non-dynamical correlation is the $\mathrm{e}_{1}^{\prime \prime}(\pi) / \mathrm{e}_{1}^{\prime \prime}\left(\mathrm{d}_{x z}\right)$ couple, with occupation numbers $(1.77 / 0.23)$ that deviate much more from 2.0/0.0 than for any of the other complexes/states. Also note from Table 3 that the RASSCF reference weight resulting from the RASPT2 calculation is similar for the $\mathrm{MnCp}_{2}{ }^{+5} \mathrm{E}_{2}^{\prime \prime}$ state than for the other cases, thus showing that the quality of the RASPT2 result should be equal. We finally also note that the stronger multiconfigurational effect in the $\mathrm{MnCp}_{2}{ }^{+} \mathrm{E}_{2}^{\prime \prime}$ is completely masked in the $\mathrm{T}_{1} / \mathrm{D}_{1}$ diagnostics, thus indicating that the latter diagnostics, by themselves, are not always a reliable guide for the quality of the $\operatorname{CCSD}(\mathrm{T})$ wave function.

\section{Comparison of computed and experimental binding energies}

Turning to the comparison between theory and experiment, we first note that for all complexes but $\mathrm{MnCp}_{2}{ }^{+}$, the most recently reported experimental binding energies, either TCID $^{9}$ or TPEPICO, ${ }^{10,11}$ quite strongly disagree, the latter method systematically giving larger values. For the complexes $\mathrm{TiCp}_{2}{ }^{+}, \mathrm{VCp}_{2}{ }^{+}$, and $\mathrm{CrCp}_{2}{ }^{+}$, the $\mathrm{CCSD}(\mathrm{T})$ binding energies (considered more accurate than RASPT2, see previous section) closely correspond 
to the TCID result in case of $\mathrm{VCp}_{2}{ }^{+}$, whereas for the other two complexes the deviation between both sets of data is much larger and differs in sign: $-6.4 \mathrm{kcal} / \mathrm{mol}$ for $\mathrm{TiCp}_{2}{ }^{+}$, $+13 \mathrm{kcal} / \mathrm{mol}$ for $\mathrm{CrCp}_{2}{ }^{+}$. For the latter molecule, the difference between $\mathrm{CCSD}(\mathrm{T})$ and TPEPICO is much smaller, at most $6 \mathrm{kcal} / \mathrm{mol}$ in absolute value. Also for the complexes $\mathrm{FeCp}_{2}{ }^{+}, \mathrm{CoCp}_{2}{ }^{+}$, and $\mathrm{NiCp}_{2}{ }^{+}$, the $\mathrm{CCSD}(\mathrm{T})$ and RASPT2 results are consistently lower, by $10-25 \mathrm{kcal} / \mathrm{mol}$ than the results reported from the TCID study, while the correspondence with the TPECICO data is considerably better. $\mathrm{MnCp}_{2}{ }^{+}$is again an exceptional case. Here, the two experimental data agree to within $2 \mathrm{kcal} / \mathrm{mol}$. However, in ref. 9 it was noted that the two different experiments may in fact have measured Cp dissociation from a different state, the triplet ground state in the TCID experiments, but the quintet state in the TPEPICO experiments, the latter excited state being initially obtained from photoionisation of the high-spin (sextet) $\mathrm{MnCp}_{2}$ complex. Both experimental data may be compared to our calculated results. For the quintet state, we find an excellent correspondence between TPEPICO and our RASPT2 result, whereas the CCSD(T) result is strongly different (but should be considered less accurate, see previous section). On the other hand, for the triplet state the binding energy obtained from TCID lies between the RASPT2 and CCSD(T) data, but closer to the latter result.

\section{Conclusion}

In this work, we have used high-level wavefunction-based methods (MP2, CASPT2, NEVPT2, and CCSD(T)), to study the $\mathrm{MCp}^{+}-\mathrm{Cp}$ bond strength of a series of first-row metallocenium ions. From a detailed analysis of the differences in these computational approaches with respect to the treatment of non-dynamical/dynamical correlation, we are able to propose a set of "best" binding energies, which we believe should be accurate to within $5 \mathrm{kcal} / \mathrm{mol}$.

For the metallocenium complexes of the early $\mathrm{TM} \mathrm{TiCp}_{2}{ }^{+}, \mathrm{VCp}_{2}{ }^{+}$, and $\mathrm{CrCp}_{2}{ }^{+}$, the binding energies obtained from $\operatorname{CCSD}(\mathrm{T})\left(105 \mathrm{kcal} / \mathrm{mol}\right.$ for $\mathrm{TiCp}_{2}{ }^{+}, 93 \mathrm{kcal} / \mathrm{mol}$ for $\mathrm{VCp}_{2}{ }^{+}$, and $110 \mathrm{kcal} / \mathrm{mol}$ for $\mathrm{CrCp}_{2}{ }^{+}$) should be considered superior to the results ob- 
tained from either MP2, RASPT2, or NEVPT2. The latter second-order perturbational methods systematically overestimate the binding energies, regardless of the size of the reference wave function (RASPT2 versus MP2) or the zeroth-order Hamiltonian (NEVPT2 versus RASPT2). For the metallocenium complexes of the late TM (Fe, Co, Ni), we have shown that the wave function contains considerably more multiconfigurational character than for the early TM. However, here the results obtained from RASPT2 (109, 131, and $97 \mathrm{kcal} / \mathrm{mol}$ for $\mathrm{FeCp}_{2}{ }^{+}, \mathrm{CoCp}_{2}{ }^{+}$, and $\mathrm{NiCp}_{2}{ }^{+}$, respectively) and $\mathrm{CCSD}(\mathrm{T})(108,129$, and $94 \mathrm{kcal} / \mathrm{mol}$ for the same series) are close to within $3 \mathrm{kcal} / \mathrm{mol}$, indicating that the latter method is indeed capable of dealing with the non-dynamical correlation effects.

The most difficult case studied is $\mathrm{MnCp}_{2}{ }^{+}$. For the triplet ground state of this molecule the binding energy obtained from RASPT2 $(86 \mathrm{kcal} / \mathrm{mol})$ is probably slightly too large, and the $\operatorname{CCSD}(\mathrm{T})$ result $(80 \mathrm{kcal} / \mathrm{mol})$ might again be more accurate. However, the latter method becomes less accurate in its description of the low-lying quintet state, showing considerably stronger multireference character than any of the other complexes/states. As a result, the quintet-triplet splitting is overestimated at the $\operatorname{CCSD}(\mathrm{T})$ level, whereas the $\mathrm{MnCp}^{+}-\mathrm{Cp}$ binding energy is underestimated. For this state the binding energy obtained from RASPT2, $81 \mathrm{kcal} / \mathrm{mol}$, should be considered superior.

As compared to experiment, our best computational results quite closely correspond to the data reported from TPEPICO, where available, while disagreeing more strongly with the (much lower) TCID data for the same molecules. For $\mathrm{TiCp}_{2}{ }^{+}, \mathrm{VCp}_{2}{ }^{+}$, and $\mathrm{MnCp}_{2}{ }^{+}$ $\left({ }^{3} \mathrm{E}_{1}^{\prime}\right)$ no TPEPICO experiments have been reported, but here the correspondence between the calculated results and the TCID experimental data is satisfactory, with a maximum deviation of $7 \mathrm{kcal} / \mathrm{mol}$ for $\mathrm{TiCp}_{2}{ }^{+}$.

\section{Supporting Information Available}

Relative energies of possible spin-state of $\mathrm{MCp}_{2}{ }^{+}$and $\mathrm{MCp}^{+}$; DFT, C(R)ASPT2, CCSD(T) bond dissociation energy of $\mathrm{MCp}_{2}{ }^{+}$; occupation numbers of the (valence) natural orbitals in the $\mathrm{MCp}_{2}{ }^{+}$and $\mathrm{MCp}^{+}$complexes. This material is available free of charge via the Internet at http://pubs.acs.org/. 


\section{Acknowledgement}

This investigation has been supported by grants from the Flemish Science Foundation (FWO). 


\section{References}

(1) Kealy, T. J.; Pauson, P. L. Nature 1951, 168, 1039-1040.

(2) Pauson, P. L. J. Organomet. Chem. 2001, 637-639, 3-6.

(3) Wilkinson, G. J. Am. Chem. Soc. 1952, 74, 6146-6147.

(4) Long, N. J. In Metallocenes: An Introduction to Sandwich Complexes; Long, N. J., Ed.; Wiley-Blackwell, 1998.

(5) Kuo, L. Y.; Kanatzidis, M. G.; Sabat, M.; Tipton, A. L.; Marks, T. J. J. Am. Chem. Soc. 1991, 113, 9027-9045.

(6) Benedikt, G. M. In Metallocene Technology in Commercial Applications; Benedikt, G. M., Ed.; William Andrew, 1999.

(7) Ryan, M. F.; Eyler, J. R.; Richardson, D. E. J. Am. Chem. Soc. 1992, 114, 86118619.

(8) Müller, J.; D'or, L. J. Organomet. Chem. 1967, 10, 313-322.

(9) Rowland, T. G.; Sztáray, B.; Armentrout, P. B. J. Phys. Chem. A 2013, 117, 12991309.

(10) Révész, A.; Szepes, L.; Baer, T.; Sztáray, B. J. Am. Chem. Soc. 2010, 132, 1779517803.

(11) Li, Y.; Sztáray, B.; Baer, T. J. Am. Chem. Soc. 2002, 124, 5843-5849.

(12) Kassel, L. S. J. Phys. Chem. 1927, 32, 225-242.

(13) Rice, O. K.; Ramsperger, H. C. J. Am. Chem. Soc. 1927, 49, 1617-1629.

(14) Rice, O. K.; Ramsperger, H. C. J. Am. Chem. Soc. 1928, 50, 617-620.

(15) Marcus, R. A.; Rice, O. K. J. Phys. Chem. 1951, 55, 894-908.

(16) Troe, J.; Ushakov, V. G.; Viggiano, A. A. J. Phys. Chem. A 2005, 110, 1491-1499. 
(17) Swart, M. Inorg. Chim. Acta 2007, 360, 179 - 189.

(18) Phung, Q. M.; Vancoillie, S.; Pierloot, K. J. Chem. Theory Comput. 2012, 8, 883892.

(19) Angeli, C.; Cimiraglia, R.; Evangelisti, S.; Leininger, T.; Malrieu, J.-P. J. Chem. Phys. 2001, 114, 10252-10264.

(20) Angeli, C.; Cimiraglia, R.; Malrieu, J.-P. J. Chem. Phys. 2002, 117, 9138-9153.

(21) Angeli, C.; Pastore, M.; Cimiraglia, R. Theor Chem Acc 2007, 117, 743-754.

(22) On the potential energy surface (PES) of $\mathrm{MCp}_{2}{ }^{+}$and $\mathrm{MCp}^{+}$, the global minimum well is rather shallow. Therefore, we expect that limited changes in the geometry should not significantly affect the results for the dissociation energy, as is illustrated by the fact that only minimal changes the CASPT2 dissociation energy (by \pm 1 $\mathrm{kcal} / \mathrm{mol}$ ) are observed when performing the CASPT2 calculations on geometries obtained with different functionals.

(23) Ahlrichs, R.; Bär, M.; Häser, M.; Horn, H.; Kölmel, C. Chem. Phys. Lett. 1989, 162, 165-169.

(24) Weigend, F.; Häser, M.; Patzelt, H.; Ahlrichs, R. Chem. Phys. Lett. 1998, 294, $143-152$.

(25) Weigend, F.; Furche, F.; Ahlrichs, R. J. Chem. Phys. 2003, 119, 12753-12762.

(26) Grimme, S.; Antony, J.; Ehrlich, S.; Krieg, H. J. Chem. Phys. 2010, 132, 154104+.

(27) Reiher, M.; Wolf, A. J. Chem. Phys. 2004, 121, 2037-2047.

(28) Reiher, M.; Wolf, A. J. Chem. Phys. 2004, 121, 10945-10956.

(29) Aquilante, F.; De Vico, L.; Ferré, N.; Ghigo, G.; Malmqvist, P.-Å.; Neogrády, P.; Pedersen, T. B.; Pitoňák, M.; Reiher, M.; Roos, B. O.; Serrano-Andrés, L.; Urban, M.; Veryazov, V.; Lindh, R. J. Comput. Chem. 2010, 31, 224-247. 
(30) Roos, B. O.; Lindh, R.; Malmqvist, P.-Å.; Veryazov, V.; Widmark, P.-O. J. Phys. Chem. A 2005, 109, 6575-6579.

(31) Roos, B. O.; Lindh, R.; Malmqvist, P.-Å.; Veryazov, V.; Widmark, P.-O. J. Phys. Chem. A 2004, 108, 2851-2858.

(32) Widmark, P.-O.; Malmqvist, P.-A.; Roos, B. O. Theor. Chem. Acc. 1990, r7, 291306.

(33) Vancoillie, S.; Zhao, H.; Tran, V. T.; Hendrickx, M. F. A.; Pierloot, K. J. Chem. Theory Comput. 2011, 7, 3961-3977.

(34) Aquilante, F.; Malmqvist, P.-A.; Pedersen, T. B.; Ghosh, A.; Roos, B. O. J. Chem. Theory Comput. 2008, 4, 694-702.

(35) Boström, J.; Delcey, M. G.; Aquilante, F.; Serrano-Andrés, L.; Pedersen, T. B.; Lindh, R. J. Chem. Theory Comput. 2010, 6, 747-754.

(36) Ghigo, G.; Roos, B. O.; Malmqvist, P.-Å. Chem. Phys. Lett. 2004, 396, 142 - 149.

(37) Forsberg, N.; Malmqvist, P.-Å. Chem. Phys. Lett. 1997, 274, $196-204$.

(38) Roos, B. O.; Andersson, K.; Fülscher, M. P.; Malmqvist, P.-Å.; Serrano-Andrés, L.; Pierloot, K.; Merchán, M. In Advances in Chemical Physics: New Methods in Computational Quantum Mechanics, Vol. XCIII:219; Prigogine, I., Rice, S. A., Eds.; John Wiley \& Sons: New York, 1996; pp 219-332.

(39) Pierloot, K. In Computational Organometallic Chemistry; Cundari, T. R., Ed.; Marcel Dekker, Inc.: New York, 2001; pp 123-158.

(40) Pierloot, K. Int. J. Quantum Chem. 2011, 111, 3291-3301.

(41) Werner, H.-J.; Knowles, P. J.; Knizia, G.; Manby, F. R.; Schütz, M. Wiley Interdisciplinary Reviews: Computational Molecular Science 2012, 2, 242-253.

(42) Balabanov, N. B.; Peterson, K. A. J. Chem. Phys. 2005, 123, 064107. 
(43) Kendall, R. A.; Thom H. Dunning, J.; Harrison, R. J. J. Chem. Phys. 1992, 96, 6796-6806.

(44) Thom H. Dunning, J. J. Chem. Phys. 1989, 90, 1007-1023.

(45) We note that the ground state electronic configuration of the $\mathrm{CoCp}^{+}$ion $\left(\mathrm{e}_{2}\left(\mathrm{~d}_{\mathrm{xy}}, \mathrm{d}_{\mathrm{x}^{2}-\mathrm{y}^{2}}\right)^{3} \mathrm{a}_{1}\left(\mathrm{~d}_{\mathrm{z}^{2}}\right)^{2} \mathrm{e}_{1}\left(\mathrm{~d}_{\mathrm{xz}}, \mathrm{d}_{\mathrm{yz}}\right)^{2}\right)$ calculated by CASSCF is different from previously reported calculations, ${ }^{9}\left(\mathrm{e}_{2}\left(\mathrm{~d}_{\mathrm{xy}}, \mathrm{d}_{\mathrm{x}^{2}-\mathrm{y}^{2}}\right)^{4} \mathrm{a}_{1}\left(\mathrm{~d}_{\mathrm{z}^{2}}\right)^{1} \mathrm{e}_{1}\left(\mathrm{~d}_{\mathrm{xz}}, \mathrm{d}_{\mathrm{yz}}\right)^{2}\right)$. Within the $\mathrm{C}_{\mathrm{s}}$ point group used in our calculations, $\mathrm{d}_{\mathrm{z}^{2}}$ and $\mathrm{d}_{\mathrm{xy}}$ belong to the same representation $\left(\mathrm{a}^{\prime}\right)$, and both configurations become the same in terms of symmetry types/occupation numbers. Our calculations show that $\mathrm{d}_{\mathrm{z}^{2}}$, not $\mathrm{d}_{\mathrm{xy}}$, is doubly occupied in the ground state.

(46) Urabe, H.; Sato, F. Encyclopedia of Reagents for Organic Synthesis; John Wiley \& Sons, Ltd, 2001.

(47) Pierloot, K.; Persson, B. J.; Roos, B. O. J. Phys. Chem. 1995, 99, 3465-3472.

(48) Jiang, W.; DeYonker, N. J.; Wilson, A. K. J. Chem. Theory Comput. 2012, 8, $460-468$.

(49) Li, X.; Paldus, J. J. Chem. Phys. 2007, 126, 234303.

(50) Pierloot, K.; Vancoillie, S. J. Chem. Phys. 2006, 125, 124303.

(51) Pierloot, K.; Vancoillie, S. J. Chem. Phys. 2008, 128, 034104.

(52) Vancoillie, S.; Radoń, M.; Zhao, H.; Pierloot, K. J. Chem. Theory Comput. 2010, $6,576-582$.

(53) Delcey, M. G.; Pierloot, K.; Phung, Q. M.; Vancoillie, S.; Lindh, R.; Ryde, U. Phys. Chem. Chem. Phys. 2014, 16, 7927-7938. 


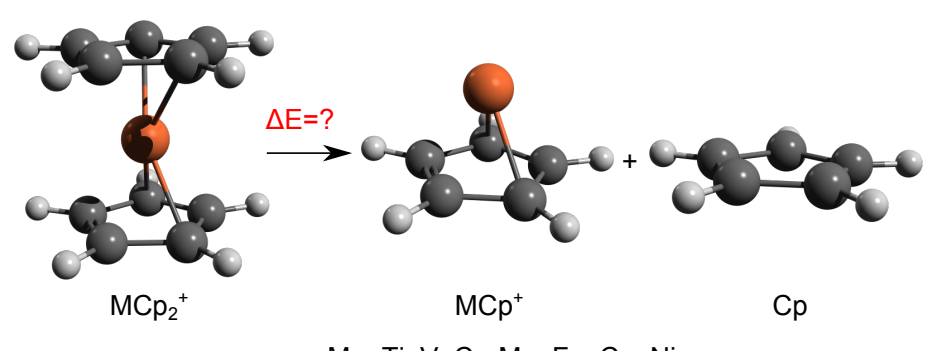

$\mathrm{M}=\mathrm{Ti}, \mathrm{V}, \mathrm{Cr}, \mathrm{Mn}, \mathrm{Fe}, \mathrm{Co}, \mathrm{Ni}$

Table of Contents - Graphic 